\title{
An investigation on the effects of organizational memory and human capital on innovation and absorptive capacity
}

\author{
Zahra Mansouri ${ }^{\mathrm{a}}$, Touran Razmavar ${ }^{\mathrm{a}^{*}}$ and Mohamad Reza Nour Ali
}

${ }^{a}$ M.sc.Student, Department of Management, Shahid Chamran University of Ahvaz, Iran

${ }^{b}$ M.Sc. Student, Department of Management, University of Shahed, Tehran, Iran

\section{H R O N I C L E \\ A B S T R A C T}

\section{Article history:}

Received December 28, 2013

Received in revised format April 152014

Accepted April 302014

Available online

May 12014

Keywords:

Organizational memory

Absorptive capacity

Human capital and Innovation
Innovation is considered as an enabling tool for creating value and sustainable competitive advantage for organizations in dynamic environment of our times along with its ever-increasing complexities. Until innovation in developing countries needs more capital and talent, human capital (HC) is a key factor in innovative performance. People are the most important factor of exploitation of foreign knowledge; and knowledge focus in business environment is highly dependent on external information sources in order to develop innovation and improve performance of the company. Studies have shown that although importance level of knowledge is increased, but only 30 percent of existing knowledge is being used in organizations. Expensive but evitable mistakes take place due to information blockage; and the risk of losing knowledge is exceptionally higher when people leave the organization. This study is among the field research. The population includes large manufacturing firms across Khuzestan Province having been active throughout 2013. The data collection tool was a structured questionnaire and sampling is convenience method. The research questionnaire was distributed among a sample of 331 R\&D and Human resources Experts selected using simple random sampling. The collected data were analyzed using SPSS and Amos statistical programs. The results indicate that organizational memory had significant impact on ACAP and innovation. Results also showed a significant positive effect of HC on ACAP, but did not support the effect of HC on innovation.

\section{Introduction}

Innovation is considered as enabling essential tools for creating value and sustainable competitive advantage for organizations in very dynamic environment of our times along with its ever-increasing complexities (Subramaniam \& Youndt, 2005). Organizations with more innovation power are more successful responding to dynamic environments and creating new capabilities for business development (Montes et al., 2004). The innovation start point is highly dependent on knowledge, expertise, and human commitment as the main inputs of value creation and innovation process. As *Corresponding author.

E-mail address: razmavar 84@yahoo.com (T. Razmavar) 
innovation in developing countries needs more capital and talents, the human capital (HC) is a key factor of innovative performance and it plays a determinant role in absorption and adaptation of overflowing technology through merchandise import, direct foreign investment input flow, and consequently development of innovative activities (Ping \& Qingchang, 2008). People are considered as the most important factor of exploitation of foreign knowledge; and knowledge focus in business environment is highly dependent on external information sources in order to develop innovation and improve performance of the company (Morgan \& Berthon, 2008). Organizational memory (OM) is another element apart from human capital, which leads to organizational innovation.

Organizations usually do not remember the reasons for their past deeds. Every organization has to gather three kinds of information continuously in order to survive. Some of these types of information include information about its surrounding environment, about its past, and finally information about internal parts and constituent elements of itself (Sadoughi et al., 2011).

Although organizations are in fact the formal or informal mechanisms intended for gathering, keeping, and using other resources (Miller \& Nilakanta, 1997), they are facing problems finding suitable equipment to acquire, to create, to transmit, and to use intellectual capital. The knowledge existing in employees' brains, in information systems and existing in organizational culture are the most valuable assets of the organizations (Sadoughi et al., 2011).

Studies have shown that although importance level of knowledge is increased, but only 30 percent of existing knowledge is being used within organizations (Lehner \& Maier, 2000). Expensive but evitable mistakes may happen due to information blockage; and the risk of losing knowledge is exceptionally higher when people leave the organization. Another study has shown that 74 percent of respondents believe the best parts of knowledge in organizations are inaccessible and 68 percent think that mistakes keep happening (Alavi \& Leidner, 2001). This study therefore, intends to examine the effect of $\mathrm{OM}$ and $\mathrm{HC}$ on innovation through evaluation of intercession role of knowledge absorption.

Leal-Rodríguez et al. (2014) studied the relationship between potential of ACAP on innovation through evaluating the intercession role of absorption capacity in the field of relational learning. The study was conducted with 110 project team managers of car parts manufacturers in Spain. They concluded that sheer recognition of ACAP plays an intercession role in relationship between potential ACAP and innovation outputs. Rahmanian and Nasr (2008) addressed the potential absorption capacity from two dimensions of inception and absorption in their study about creating absorption capacity for organizing open innovations in small and medium size industries of Markazi province, Iran. Their research findings showed that ability of experts and competence of human personnel was an important factor, which influences on potential absorption capacity. They also stated that education and improvement of HC should be addressed first in order to develop ACAP.

Some other people examined the effect of internal and imported research and development and HC on innovation in China over the period 1990-2005 period. Research results suggested that although the effect of international technology propagation on innovation was not negligible, but stack of internal research and development activities act as the innovation engine for China. Gray (2006) examined the capacity of small entrepreneurial companies for knowledge absorption and management since he believed that capacity of knowledge absorption and management was a prerequisite of success in innovation and entrepreneurial grows. Camison and Lopez (2011) studied the role of OM and learning capabilities on non-technological innovation improvement and achieving sustainable competitive advantage. They conducted their study in Spanish manufacturing firms and concluded that the stronger OM, the faster it achieves (organizational and marketing) innovation and competitive advantage, the faster it leads to better performance for organization. Hoseini and Hajipour (2008) addressed the subject of stating common mind relationships, ACAP, innovation and flexibility of medicine companies. They concluded that common perspective of HC will directly influence the ACAP through a direct and significant relationship. 


\section{Theoretical bases}

\subsection{Organizational memory}

Walsh and Ungson (1991) stated OM as a concept in details and many researchers have worked on it since then; and some kind of confusion has been created about how to use this concept (Heijst, 1996). There are literally various definitions for OM, such as: knowledge is a key capital for organizations. OM develops and reinforces the knowledge created by company personnel through inception, organization, propagation and reusing that knowledge (Conklin, 1996). Mechanisms of OM are supposed to acquire and to preserve the knowledge inside an organization while making it retrievable and reusable (Dzbor \& Paralic, 2000). This study uses indices of communications, adding to knowledge, and environmental adaptation to evaluate this variable.

\subsection{Human Capital at Firm level (Firm-Level HC)}

Unique level and configuration of supplementary characteristics of employees are suitable for satisfying customer demands and acquiring economic value along with organizational value and goals. Quantity, congruence, complementarity, and specificity are considered as four dimensions of $\mathrm{HC}$ at firm level. Firm-level $\mathrm{HC}$ is evaluated and examined through the mean value of quantities namely: Quantity of Human Capital, HC-organization congruence, complementarity among HC, and specificity of HC (Rahimi, 2010).

\subsection{Absorption capacity (ACAP)}

ACAP is the ability of a particular company to evaluate and to use external knowledge from firm's environment, i.e. higher absorption capacity including more training, employee expansion and intention towards technology causes better organizational performance (Colin, 2006; Zahra \& George, 2002). ACAP includes configuring processes and procedures used by the firms to accumulate, to absorb, to transfer, and to implement knowledge. Absorption capacity is measured in that research by same previous indices associated with organization business, communication atmosphere, environment scanning methods and R\&D.

\subsection{Innovation}

Innovation is the process of translating knowledge into economic growth and social improvement. It includes a set of scientific, technological, organizational, financial and business activities. Innovation emerges in societies as the process of introducing and commercializing products or services, or fundamental improvement of existing processes, opening doors of new markets, and developing new supply resources such as raw materials, equipment, and other inputs, and fundamental changes in industrial and organizational structures. Innovation plays a determinant role in economic growth and development (Puga \& Trefler, 2010).

\subsection{Research Hypotheses}

According to the above hypotheses and research model is mentioned as follows.

Hypothesis 1: OM has significant effect on ACAP.

Hypothesis 2: OM has significant effect on innovation.

Hypothesis 3: HC in the firm level has significant effect on ACAP.

Hypothesis 4: HC in the firm level has significant effect on innovation.

Hypothesis 5: ACAP has significant effect on innovation. 


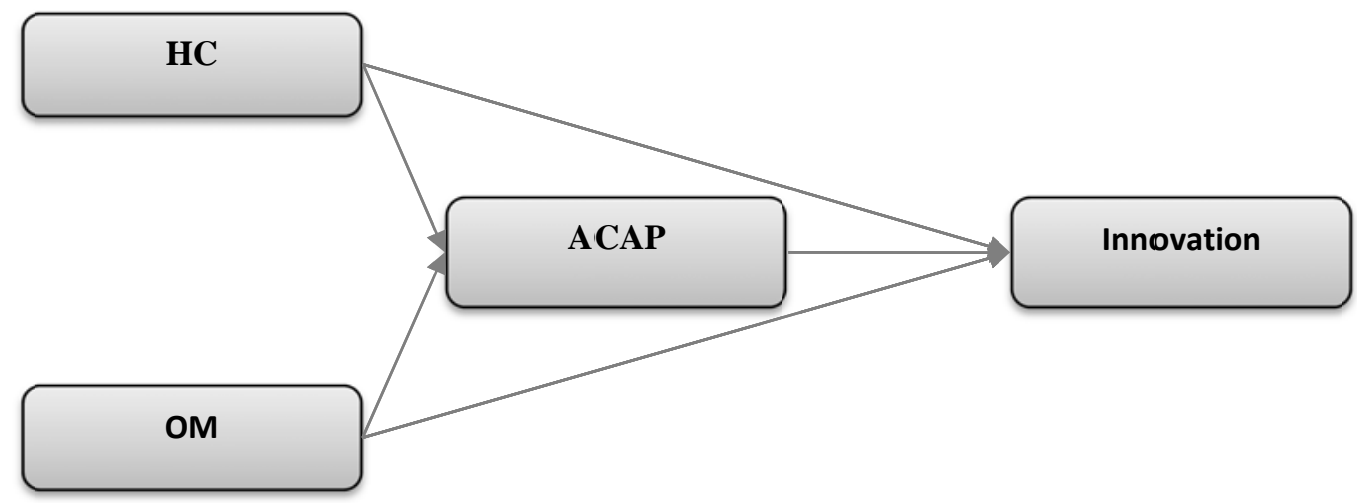

Fig 1: The research model

\section{Method}

\subsection{Data collection}

A structured questionnaire was used as a data collection tool. All questions were measured by a five choice Likert scale (fully agree, to fully disagree). Validity of research context was approved by three experts in this field, who had considerable executive and educational records. Method of "Cronbach alpha" was used to evaluate stability of the questionnaire; and gave the value of 0.895 , which shows high level of stability for that. The questionnaire included two groups of questions: general questions (including demographic characteristics if sample under study), and specialty questions in the field of OM, human capital, ACAP, and innovation. The population includes large manufacturing firms, which are active during 2013 in Khuzestan Province. Convenience sampling was applied to select the sample members. The research questionnaire was distributed among $R \& D$, and human resources experts. 372 questionnaires were collected among which 41 were discarded and the rest 331 were analyzed.

Among 331 respondents, $282(85.2 \%)$ were male and 49 (14.8) were female. $21.8 \%$ had secondary and lower-secondary education; $16.9 \%$ had Associate degree; 43.8\%, Bachelor degree; 16.3\%, Master degree; and 1.2\%, $\mathrm{PhD}$ degree.

\subsection{Measures}

Confirmatory Factor Analysis (CFA) method Analysis by the use of Amos software was used as the evaluation method for questionnaire suitability; and results are shown in Table 1. CFA results obtained for all measuring methods confirmed that data collection methods were suitable. According to Table 1, it can be seen that all the 4 measuring models meet the mentioned conditions and are suitable models. These results indicate that the questionnaires of this research have proper validity and reliability. Cronbach's $\alpha$ are $\mathrm{OM}=0.889, \mathrm{HC}=0.899, \mathrm{ACAP}=0.884$ and Innovation $=0.895$.

\section{Table 1}

Measurement model summary

\begin{tabular}{llllll}
\hline Goodness of fit measures & Criteria & HC & OM & ACAP & Innovation \\
\hline Chi-square & - & 2.35 & 4.42 & 5.11 & 7.59 \\
Chi-square/degree of freedom & $\geq 3$ & 1.175 & 2.31 & 2.55 & 1.51 \\
GFI & $\geq 0.90$ & 0.99 & 0.97 & 0.98 & 0.98 \\
RMSR & $\geq 0.10$ & 0.085 & 0.082 & 0.086 & 0.05 \\
NFI & $\geq 0.90$ & 0.99 & 0.98 & 0.97 & 0.97 \\
NNFI & $\geq 0.90$ & 0.95 & 0.97 & 0.98 & 0.98 \\
CFI & $\geq 0.90$ & 0.99 & 0.99 & 0.99 & 0.99 \\
AGFI & $\geq 0.90$ & 0.92 & 0.93 & 0.91 & 0.95 \\
\hline
\end{tabular}




\section{Results}

After evaluation and approving the pattern, two partial indices of critical values $\mathrm{CR}$ and $\mathrm{P}$ were used for testing significance level of the hypotheses. At 95 percent significance level, the critical value has to be higher than 1.96 or lower than -1.96. The parameters whose values are located between these two limits are not considered as significant in this sample. In addition, values lower than 0.05 for $\mathrm{P}$ state that there is a significant difference between calculated values of regression weights with zero value at 95 percent certainty level. Results of fit indices, acceptable threshold and their situations for proposed model are shown in Table 2.

\section{Table2}

Results of SEM

\begin{tabular}{llllll}
\hline Hypothesis & Estimate & S.E & C.R. & P & Support / Reject \\
\hline OM- ACAP & 0.388 & 0.059 & 6.622 & 0.000 & Support \\
OM- Innovation & 0.967 & 0.14 & 6.889 & 0.000 & Support \\
HC-ACAP & 0.828 & 0.079 & 10.439 & 0.000 & Support \\
HC- Innovation & 0.019 & 0.087 & 0.22 & 0.825 & Reject \\
ACAP- Innovation & 0.516 & 0.115 & 4.487 & 0.000 & Support \\
\hline
\end{tabular}

Chi-Square $/ \mathrm{df}=3.094, \mathrm{NFI}=0.924, \mathrm{NNFI}=0.914, \mathrm{GFI}=0.882, \mathrm{CFI}=0.947, \mathrm{RMSEA}=0.08$

Considering critical ratio values and significance levels, the results show that $\mathrm{OM}$ and HC both positively and significantly influence ACAP. OM and ACAP influence innovation positively and significantly as well. However, no positive significant relationship was found between $\mathrm{HC}$ and innovations.

\section{Conclusion}

This article has addressed the issue of examining the effect of OM and HC on innovation and ACAP. The results of this study show that OM influence ACAP positively and significantly, which confirms previous researches. Also results show a positive and significant effect of $\mathrm{HC}$ on ACAP, which is in accordance with Rahmanian and Nasr (2008), and Hoseini and Hjipour (2008). The significant effect of OM on innovation was supported as well which is in congruence with researches conducted by Camisón and Villar-López (2011) and Hanvanich et al. (2006). However, existence of the significant effect of $\mathrm{HC}$ on innovation was rejected and this is not in accordance with other survey results. Existence of a significant effect of ACAP on innovation was approved as well. This is in concordance with Grey (2006).

These results underscore the vital and important role of ACAP within innovation process, i.e. higher level of ACAP can lead to creative and innovating thoughts. Results of this study can be useful for theoretical development of a conceptual model, which could describe the effect of OM, human capital, ACAP, and innovation.

\section{References}

Alavi, M., \& Leidner, D. E. (2001). Review: Knowledge management and knowledge management systems: Conceptual foundations and research issues. MIS quarterly, 25(1), 107-136.

Camisón, C., \& Villar-López, A. (2011). Non-technical innovation: organizational memory and learning capabilities as antecedent factors with effects on sustained competitive advantage. Industrial Marketing Management, 40(8), 1294-1304.

Colin, G. (2006). Absorptive capacity, knowledge management and innovation in entrepreneurial small firms, International Journal of Entrepreneurial Behaviour \& Research, 12(6), 345-360.

Conklin, J. (1996). Capturing Organisational Memory, in Groupware and Computer- Supported Cooperative Work. R.M. Barcker (Ed.), Morgan Kaufman, 561-565. 
Dzbor, M., \& Paralic J. (2000). Knowledege Management in a distributed Organization Kmi- TR-94 technical report, Knowledge Media Institute, Open University.

Gray, C. (2006). Absorptive capacity, knowledge management and innovation in entrepreneurial small firms. International Journal of Entrepreneurial Behaviour \& Research, 12(6), 345-360.

Hanvanich, S., Sivakumar, K., \& Hult, G. T. M. (2006). The relationship of learning and memory with organizational performance: the moderating role of turbulence. Journal of the Academy of Marketing Science, 34(4), 600-612.

Heijst, G.V., Spek, R.V., \& Kruizinga, E. (1996). Organizing corporate memories, computer based learning unit. University of Leeds.

DeHoog, K. R. (1994). Towards a methodology for knowledge management, Technical Note knowledge management network.

Leal-Rodríguez, A. L., Roldán, J. L., Ariza-Montes, J. A., \& Leal-Millán, A. (2014). From potential absorptive capacity to innovation outcomes in project teams: The conditional mediating role of the realized absorptive capacity in a relational learning context. International Journal of Project Management.

Lehner, F., \& Maier, R.K. (2000). How can organizational memory theories contribute to organizational memory systems? Information Systems Frontiers, 2(3-4), $277-98$.

Miller, L., \& Nilakanta, S. (1997). Tools for organizational decision support: The sesign and development of an organizational memory system. Proceedings of the Annual Hawaii International Conference on System Sciences (CD-ROM) of ABC Software; Maui, Hawaii.

Montes, F. J. L., Moreno, A. R., \& Fernández, L. M. M. (2004). Assessing the organizational climate and contractual relationship for perceptions of support for innovation. International Journal of manpower, 25(2), 167-180.

Morgan, R. E., \& Berthon, P. (2008). Market Orientation, Generative Learning, Innovation Strategy and Business Performance Inter-Relationships in Bioscience Firms. Journal of Management Studies, 45(8), 1329-1353.

Ping, L., \& Qingchang, Z. (2008). The effects of technological spillover through FDI and import trade on China's innovation. School of Economy of Shandong University of Technology.

Puga, D., \& Trefler, D. (2010). Wake up and smell the ginseng: International trade and the rise of incremental innovation in low-wage countries. Journal of Development Economics, 91(1), 64-76.

Rahimi, F. A. (2010). Model is designed to invest in human resources to gain a competitive advantage in the knowledge-based industries. Thesis, Shahid Beheshti University.

Rahmanian, S., \& Nasr, M. (2008). Build capacity for the organization of open innovation in SME's. Fourth National Conference of Iranian Technology Management.

Sadoughi, F., Abedi fard, A., Ahmadi, F., \& Piri Zakiye, M. (2011). Process-oriented model of corporate memory, prerequisite knowledge management implementation in the medical records department. Health Information Management, 8(6), 743-756.

Subramaniam, M., \& Youndt, M. A. (2005). The influence of intellectual capital on the types of innovative capabilities. Academy of Management Journal, 48(3), 450-463.

Walsh, J. P., \& Ungson, G. R. (1991). Organizational memory. Academy of Management Review, 16(1), 57-91.

Zahra, S. A., \& George, G. (2002). Absorptive capacity: A review, reconceptualization, and extension. Academy of Management Review, 27(2), 185-203. 